\title{
State-of-the-Art Duolingo Features and Applications
}

\author{
Stamatia Savvani \\ University of Nicosia \\ s.tia.sava@gmail.com
}

\begin{abstract}
Duolingo is a rapidly growing on-line platform for language learning. In this paper learning theories that are embodied in its design are analyzed and certain shortcomings are identified. In the past two years, Duolingo has expanded its platform with the addition of new applications and features. State-of-the-art updates are reviewed in order to uncover whether they address limitations of Duolingo's original design or provide enhancements to the learning platform.
\end{abstract}

\section{Introduction}

Duolingo is a web-based language learning platform [10], available as a mobile application. Duolingo's manifesto [2] states that the purpose of the platform is to provide the user with free, fun and personalized education to users globally. How do users learn? The main method that is employed is the translation method. Users are asked to elicit the meaning of sentences in the target language and provide the translation of the sentence in their native language or a language they know well. An extensive and thorough language skill tree guides users through their language learning. Every skill, that consists of two or more lessons, is dedicated to a specific grammar or vocabulary topic. Users are expected to translate sentences, complete matching exercises (match pictures with the corresponding word, or match a word with its definition in the target language) and thus advance in their learning through repetition of vocabulary and grammar structures.

Duolingo's efficiency in language learning has been examined and researchers have concluded that it may be a promising supplementary tool for language learning but does not provide the learner with authentic language [14] [28]. When it was introduced in language classrooms, it was observed that it promotes selfdirected learning $[24]$ and that it can promote learning two languages at the same

Duolingo $囚$, Tinycards @and all other trademarks, service marks, graphics and logos used in connection with the Service are trademarks or service marks of Duolingo or their respective owners, and certain of them are registered with the United States Patent and Trademark Office. 
time [17]; certain limitations were noticed regarding accuracy of translations and the absence of advanced language use.

Since its public release in June 2012, Duolingo has been appended with new languages (currently counting 32 languages available for English Speakers [3]). Most importantly, new features and applications, such as Labs and Tinycards [6, 9] (see Section 3) are also introduced soliciting innovative ways of learning and interacting. Learning principles other than the translation method are welcomed.

In this paper, we will first identify and comment on learning theories embedded in Duolingo's original design (Section 2). In the sections that follow, the new features that are added in Duolingo and have not been previously assessed will be reviewed. Our goal is to critically analyze Duolingo as an example of a successful learning on-line application and draw insights for its future developments as well as for similar digital game language learning applications.

\section{Key learning theories in a typical Duolingo lesson}

Duolingo embraces tenets of the Grammar-Translation method [26], Audiolingual method [25] and Digital Game Based Language Learning [13]. In the sections that follow, we analyze how Duolingo's structure is influenced by these language learning theories and identify their strengths and drawbacks.

\subsection{Grammar Translation method}

Studying a language through text translation is one of the premature methods in language teaching. Learners in Duolingo are expected to translate sentences in the target language by memorizing vocabulary and grammar structures. Below we revisit learning principles of the Grammar Translation method [26] that are found in the layout of Duolingo lessons.

Learners make constant transfers from L1 (one's mother, native or first language) to L2 (one's foreign, second or target language). Duolingo users are expected to understand sentences in L2 while they are given the definition of each word in the sentence in L1. Thus, they are asked to provide a translation for this sentence by employing cognitive skills. Reverse translation (from L2 to L1) is also endorsed in Duolingo.

Similar to the Grammar Translation method, Duolingo encourages accuracy. For instance, a sentence will be regarded as incorrect if the article "el" in Spanish is translated as "a or an" instead of the correct "the". However, Duolingo shows leniency for typos and forgives the absence of accents in languages such as Spanish or French, or non capitalization of the nouns in German. In case the user does not use accents or proper capitalization, the translated sentence is not regarded as incorrect but a note is displayed underlining the proper format.

Our main concerns towards employing the Grammar Translation method are that spoken language is ignored and that the user is constantly viewing L2 in

regards to L1. In addition to this, users fail to attain the cultural perceptions of L2, as L1 remains their one and only reference point. 


\subsection{Audiolingual method}

Duolingo embodies practices and theories of the Audiolingual method (ALM), which was developed in the 60 s to help learners develop oral proficiency. It is a behaviorist theory in its essence [12], as the learners are led to a self-discovery of rules; then they are drilled on the rules and are rewarded for correct responses. Although Duolingo does not focus on speaking skills, we can find principles of ALM in its lesson structure. Below typical exercises of the ALM are listed that are present in Duolingo lessons [25]:

1. Replacement: a word is replaced with another word of the same speech category or topic. For instance, users learning Spanish from English are introduced to sentences like "yo como manzanas" (i.e. "I eat apples") and then a sentence like this "yo como fresas" (i.e. "I eat strawberries") appears. This drills students in a certain grammar structure. In this case, the verb "como" is taught while previously learned vocabulary is revised, e.g. "manzanas", and new words are introduced, e.g. "fresas".

2. Inflection: Users are asked to repeat certain structures where the form of a word is changed. For example, first the learner is introduced to singular nouns and then the same nouns are presented in the plural form in the following lesson.

3. Restoration: the user is given a set of words and is asked to put them into the correct order so as to form a correct grammatical sentence.

These type of exercises involve repetition and drilling. However, such practices of ALM have received criticism. Linguist Noam Chomsky [12] argued that creativity in language is overlooked in ALM and behaviorism, which views language as a habit structure. Chomsky argues that the infinite utterances that a human can develop in a certain language cannot possibly be learned through repetition and reinforcement techniques.

Moreover, meaningful context is lacking in Duolingo. Even though the organization of the skill tree in Duolingo is carefully thought through, sentences in the lessons are decontextualized. Hence, the learner fails to relate to the language under instruction [14]. This drawback seems to be resolved in Duolingo's new Stories feature, see Section 3.3.

\subsection{Digital Game Based Language Learning}

Duolingo is an example of Digital Game Based Language Learning (DGBLL) applications. DGBLL concerns "the design and use of a diverse array of digital games for the purpose of learning or teaching a second or foreign language" [13]. Edutainment that is defined as "a hybrid mix of education and entertainment that relies heavily on visual material, on narrative or game-like formats, and on more informal, less didactic styles of address" [15, p.282] is prevalent in Duolingo. Following an adaptive digital game based learning framework, three elements seem to be core to edutainment design: Multimodal (interaction factors, multimedia elements and narrative), Task (completion of challenges) and 
Feedback (assessment of progress and rewards that are meant to stimulate users' motivation) [27]. The way these elements are implemented in a game environment can determine its success. Below we give examples of how these elements manifest themselves in Duolingo:

1. Multimodal: sound effects for completing lessons and making correct translations, visuals for new vocabulary words, audio for every word that is present in the sentences in L2

2. Task: complete lessons, reach the highest level in each lesson

3. Feedback: achievements (badges awarded when users complete predetermined actions), experience points and crown levels (both are awarded upon completing lessons)

Multimedia elements are abundant in Duolingo and language is delivered in different forms (audio, textual, images). Nevertheless, narrative (referred to as storytelling), a commonly underlined element of multimodal DGBLL [16], [21], is not found in Duolingo. A mystery or drama can keep players engaged in a game [21]. In Duolingo's design this element of interaction is not present as users are not introduced into a world, or characters. In Duolingo, users are asked to complete challenges; however there is not the least flavor text that will invite the learners into their next challenge.

Users are motivated as they are awarded experience points by completing the daily goals they have set a priori. In order to ensure learners' adherence to the goals, their progress in learning should be made clear to them at all times [31]. Duolingo's skill tree is clear and the learner can see how many lessons are remaining until the completion of a skill. However, a recent addition called Crown levels does not provide information to the users regarding how far they are from reaching the top crown level. This has caused frustration and discouragement amongst users as it can be observed in the application's forum $[5,4]$.

\section{New features and applications of Duolingo}

Some of Duolingo's newest features are embedeed in the platform: e.g. Duolingo Labs (released on December 21, 2017 and in experimental stage) [1], while others are located on different platforms e.g.: Tinycards [9] (released on July 19, 2016) and Duolingo for Schools [7] (released on January 8, 2015). Reviews of Labs and Tinycards are not available in academic literature. Thus, below we provide insight for these applications and suggest further research on their efficiency.

\subsection{Duolingo for schools}

A powerful resource for teachers is Duolingo for schools [7]. Teachers can organize classes and have their students sign up in them. For every class the teacher can set specific assignments that will be visible to all students enrolled in the particular classroom. The assignments are regular Duolingo lessons and the student accounts are similar to a regular account of Duolingo. What changes is 
the teacher's account, through which the teacher can track students' progress. Analytic statistics available to the teacher are gathered from students' logs and include the number of completed lessons, the number of assignments they completed on time or late, as well as the points they earned in each log.

The Duolingo for schools resource could be enhanced further by incorporating its own game elements. For instance, teacher-users could be given the ability to set long term goals for each class and run competitions between classes of the same level in order to determine which class meets the goals first, or which class gathers the most points. Badges on language learning platforms have proved to have a positive effect on learner's self-efficacy and language development [29]. Therefore, achievements could also be added in Duolingo for schools, which would be awarded not to an individual but to a class as a whole for completing a series of assignments or goals. Additions as such could spark both competition and collaboration amongst students and can provide extra motivation while working towards a common goal.

The greatest advantage of Duolingo for Schools is that with its immediate feedback to the user and the teacher, it promotes "visible learning" [19]. Both sides are allowed to measure learning and detect both weaknesses and strengths in particular linguistic concepts.

\subsection{Duolingo Labs}

Duolingo Labs include: Stories, Podcasts and Events. In Events, language learners can organize meet ups in their hometown and invite their fellow learners in order to interact in the target language. The potential significance of this feature will not be analyzed in this paper as it is meant for social settings rather than an on-line learning environment.

Duolingo Podcasts are true stories narrated in audio format; podcasts are currently available only in Spanish for English speaking learners. They aim to familiarize the learners with the target language in different meaningful contexts. According to a review of studies on the efficiency of podcasts [18], it has been proven that the incorporation of podcasts in language learning is beneficial both to learners' linguistic performance and engagement.

Duolingo Podcasts seem promising from an educational perspective and can provide learners with authentic L2 material. Moreover, the designers of the platform could consider adding listening comprehension exercises that will check users' understanding of spoken language. In this way, the potential merits of Duolingo Podcasts could be evaluated based on users' responses.

\subsection{Duolingo Stories}

Duolingo Stories [8] are short humorous stories that help learners practice their language comprehension skills. Currently, they are available in French, Spanish, Portuguese and German. Users can listen to the narration of the story and they are also provided with the textual form of the story. 
Stories are meant to be entertaining and they are also somewhat interactive. Although users cannot alter the plot or the end of the story, the narration of the story pauses at critical points and waits for the user's input. The platform generates closed-ended questions that test readers' understanding of words and content of the story. Comprehension questions during the narration check in present time whether the users are following and understanding the narration, allowing them time to reread the parts they did not understand and then proceed with the story. Computer-Assisted Language Learning (CALL) applications are argued to be more beneficial to learners' vocabulary acquisition than learning L2 vocabulary with teachers' assistance, as the first promote self-paced and autonomous learning [30]. Frequent pauses in narration can climax reader's interest in the story, as well.

Even though a word's meaning can be deduced from the context that it is found in, it may be distressing to readers if there is a significant number of unknown words in a sentence. For this reason, glosses are provided within the stories in Duolingo. Nation defines a gloss as a "brief definition or synonym, either in L1 or L2, which is provided with the text" [22, p.238]. A gloss can have different formats, e.g. text, picture, audio or a combination of these. In Duolingo Stories, when users hover their mouse over words from the text they are unfamiliar with, the gloss is displayed in textual form and the words are translated in the user's L1 (see Fig.1).

\section{Cuidando un pájaro}

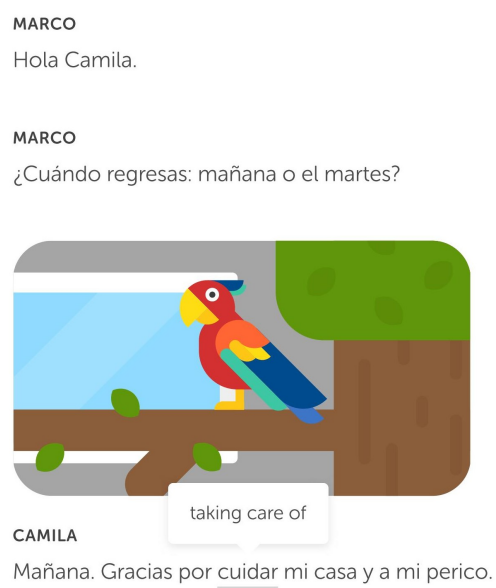

Fig. 1. A gloss in Duolingo Stories [8]: "cuidar" defined as "taking care of" [9]. Screenshot by author. 
In a typical Duolingo lesson, some sentences to be translated by the user sound unnatural e.g. "Yo soy un oso", which translates to "I am a bear" [23]. Apparently, these sentences exist to drill the user on thematic vocabulary, e.g. animals, combining it with previously learned grammar, e.g. the verb "to be". Stories resolve this awkwardness by providing meaningful content to the vocabulary expected to be acquired by the user. We support the need to move away from behaviorist CALL and explore communicative CALL applications [20], which will focus on meaning rather than repetition of odd and out of context language chunks.

\subsection{Tinycards}

Users of Tinycards [9] (available for learners of Spanish, English and Portuguese) can choose to complete or create lessons with the aid of customizable digital flashcards, called Tinycards. Users are expected to use their own ideas, images and text to create sets of Tinycards that will review certain vocabulary, grammar or other non-linguistic topics and terms from sciences like architecture, biology etc., always in the target language. Every Tinycard is two-sided (see Fig. 2); thus, on one side the user can have textual input and on the other side a picture that corresponds to the particular text. The platform enables users to upload pictures from their own devices or the web.

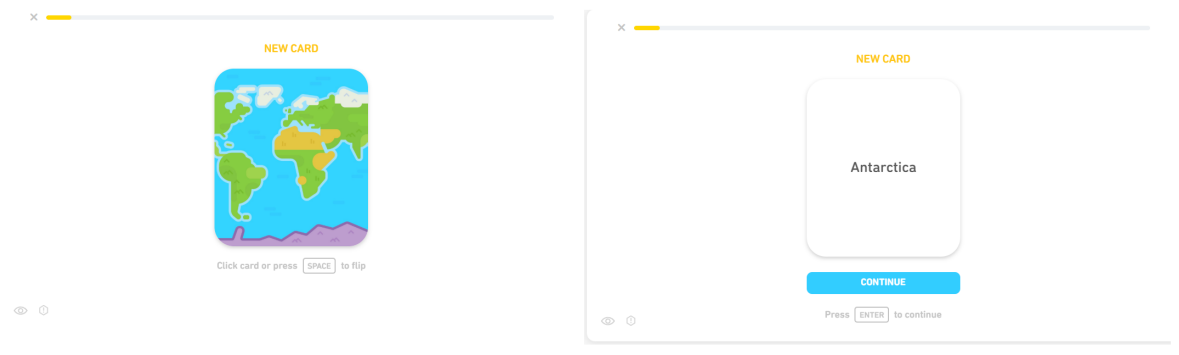

Fig. 2. A flashcard in Tinycards [9]. Screen-shot by author.

Users can organize these digital flashcards in decks in order to create a lesson, which can remain private or can be made available to other users in order to study it. In contrast to Duolingo's regular lessons, users who choose to complete a lesson in Tinycards are not asked to translate sentences. They are first shown the digital flashcards, and after they have reviewed them, they are given matching exercises (matching the correct word to the picture) or asked to type in the correct word for the image provided. However, Tinycards do not award experience points or badges to the players or creators of lessons.

From an educational viewpoint, the quality of the lessons, which are produced by users and not by Duolingo, is questionable as the lessons are reviewed by 
other users who may not be proficient in the target language. Nevertheless, Tinycards do not only target remembering and comprehension skills but also address higher order thinking skills such as evaluating and creating (according to Bloom's taxonomy [11]), when users attempt to produce their own lessons (see Fig. 3). However, Tinycards lack edutainment elements mentioned in Section 2.3 , such as experience points and advancing levels. Therefore, users' motivation could be stimulated if such elements were incorporated in Tinycards.

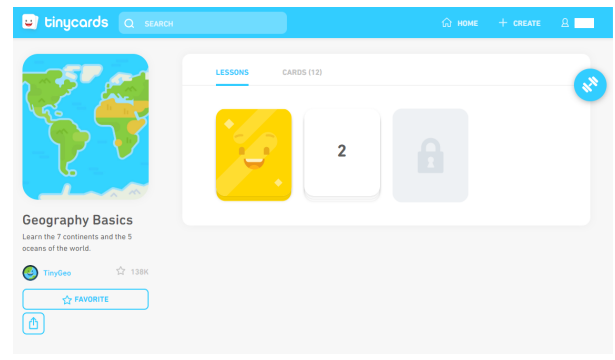

Fig. 3. A lesson in Tinycard [9]. Screen-shot by author.

\section{Conclusion}

Uncovering the learning methods that Duolingo encompasses, we have identified certain shortcomings. The translation method might be a "safe" method, preferred for teaching beginners, as L1 is used as reference. However, it is not ideal for advanced language levels and does not promote creativity. Rote repetition exercises, encouraged by the ALM method, provide the learner with sufficient practice but not with exposure to meaningful language.

Duolingo's game design could also be enhanced by providing the user with clearer, meaningful language goals and a more personalized experience through narrative. Personalization and meaningfulness could be achieved by asking the personal interests of each user. The platform could then direct users to individualized lessons that would incorporate language related to their interests.

Do the newest Duolingo features address the above summarized limitations? We would argue that some of these limitations are indeed addressed. Duolingo for schools is a great asset that complements the language classroom with immediate feedback from learners. Labs offer a more authentic language experience to the user, as Podcasts provide real-life narratives, and the engaging plot and interactivity of Duolingo Stories offer slightly more advanced language and meaningful context. Tinycards encourage (and rely on) creative skills of users, moving away from rote repetition exercises. Nevertheless, none of the above mentioned features address the absence of practicing oral communication in L2.

Despite their strengths, we have identified several weaknesses regarding recent Duolingo updates. Duolingo for Schools resource only allows the teacher 
to view student logs. While privacy concerns are valid, collaboration or positive competition could be cultivated if students were aware of their classmates' progress, or if classes were awarded badges as a whole for completing tasks set by the teacher. Podcasts do not give any feedback to learners; if they were implemented as listening exercises, they could test users' understanding of spoken language. The accuracy of language in Tinycards lessons can be questioned, as flashcards can also be created by non-native speakers or beginner users of the target language.

Overall, we encourage the addition of more advanced language content and the release of the newest features, reviewed in this paper, for learners of other languages. As the new Duolingo features seem to support the shift for a more authentic and meaningful language experience, we call for further research towards their efficiency and enhancement.

\section{References}

1. Duolingo. https://duolingo.com/, accessed: 2018-06-14

2. Duolingo: About us. https://www.duolingo.com/info, accessed: 2018-06-26

3. Duolingo courses. https://www.duolingo.com/courses, accessed: 2018-06-26

4. Duolingo discussion topic: crown levels: a horrible invention. https://forum.duolingo.com/comment/26840788, accessed:2018-06-25

5. Duolingo discussion topic: Crown levels not an improvement. https://forum.duolingo.com/comment/26846381, accessed:2018-06-25

6. Duolingo labs. https://www.duolingo.com/labs, accessed: 2018-06-14

7. Schools, duolingo. https:https://schools.duolingo.com/, accessed: 2018-06-14

8. Stories. https://stories.duolingo.com/, accessed: 2018-06-14

9. Tinycards. https://tinycards.duolingo.com/, accessed: 2018-06-14

10. What is duolingo? https://support.duolingo.com/hc/en-us/articles/204829090What-is-Duolingo-, accessed: 2018-06-26

11. Anderson, L.W., Bloom, B.S., Krathwohl, D.R.: A taxonomy for learning, teaching, and assessing. Longman (2000)

12. Byram, M.: Audiolingual method. In: Routledge Encyclopedia of Language Teaching \& Learning, pp. 58 - 60. Taylor \& Francis Ltd/ Books (2000)

13. Cornillie, F., Thorne, S.L., Desmet, P.: Digital games for language learning: from hype to insight? ReCALL 24(3), 243-256 (2012)

14. Cunningham, K.J.: Duolingo. The Electronic Journal for English as a Second Language 19(1), 1 - 9 (2015)

15. David Buckingham, M.S.: Parental pedagogies:an analysis of british edutainment magazines for young children. Journal of Early Childhood Literacy 1(3), 281-299

16. Embi, Z.C.: The implementation of framework for edutainment: Educational games customization tool. In: Proceedings of the International Symposium on Information Technology. vol. 1, pp. 1-5 (2008)

17. Essa Ahmed, H.B.: Duolingo as a bilingual learning app: a case study. Arab World English Journal 7(2), 255 (2016)

18. Hasan, M.M., Hoon, T.B.: Podcast applications in language learning: A review of recent studies. English Language Teaching 6(2) (2013)

19. Hattie, J.: Visible learning: a synthesis of over 800 meta-analyses relating to achievement. Routledge, London; New York (2009) 
20. Jeffrey Earp, T.G.: Narrative-oriented software for the learning of a foreign language. In: Giuliana Dettori, Tania Giannetti, A.P., Vaz, A. (eds.) TechnologyMediated Narrative Environments for Learning, pp. 27-40. Sense Publishers (2016)

21. Kevin, Y.: Pedagogical gamification. To Improve the Academy 32(1), 335-349

22. Nation, I.S.P., Hunston, S.: Learning Vocabulary in Another Language. Cambridge Applied Linguistics, Cambridge University Press, 2 edn. (2013)

23. Nushi, M., Hosein Eqbali, M.: Duolingo: A mobile application to assist second language learning. Teaching English with Technology 17, 89-98 (01 2017)

24. Pilar, M.: The case for using duolingo as part of the language classroom experience. Revista Iberoamericana de Educacin a Distancia 19(1), 83-109 (2016)

25. Richards, J.C., Rodgers, T.S.: The Audiolingual Method, p. 5070. Cambridge Language Teaching Library, Cambridge University Press, 2 edn. (2001)

26. Richards, J.C., Rodgers, T.S.: A brief history of language teaching, p. 317. Cambridge Language Teaching Library, Cambridge University Press, 2 edn. (2001)

27. Tan, P.H., Ling, S.W., Ting, C.Y.: Adaptive digital game-based learning framework. In: Proceedings of the 2nd International Conference on Digital Interactive Media in Entertainment and Arts. pp. 142-146. ACM (2007)

28. Teske, K.: Duolingo. CALICO Journal 34(3), 393-401 (2017)

29. Yang, J.C., Quadir, B., Chen, N.S.: Effects of the badge mechanism on self-efficacy and learning performance in a game-based english learning environment. Journal of Educational Computing Research 54(3), 371 - 394 (2016)

30. YiHui, C.: Computerassisted second language vocabulary instruction: A metaanalysis. British Journal of Educational Technology 44(2), E52-E56

31. Zoltan Dornyei, C.M., Ibrahim, Z.: Directed motivational currents. In: Lasagabaster, D., Doiz, A., Sierra, J.M. (eds.) Motivation and Foreign Language Learning : From Theory to Practice., chap. 1, pp. 9-29. John Benjamins Publishing Company (2014) 